\title{
REFERENCES
}

Annau, E., Banga, I., Blazso, A., Brukner, V., Laki, K., Straub, F. B. \& Szent-Györgyi, A. (1936). Hoppe-Seyl.Z. 244, 105.

Annau, E., Banga, I., Gözsy, B., Huszak, S., Laki, K., Straub, F. B. \& Szent-Györgyi, A. (1935). Hoppe-Seyl. Z. 236, 1.

Annau, E. \& Erdös, T. (1939). Hoppe-Seyl. Z. 257, 111.

Banga, I., Ochoa, S. \& Peters, R. A. (1939). Biochem. J. 33, 1980.

Das, N. B. (1937a). Biochem. J. 31, 1116.
Das, N. B. (1937b). Biochem. J. 31, 1124.

Fenton, H. J. H. \& Jones, H. O. (1900). J. chem. Soc. 77, 69.

Gözsy, B. \& Szent-Györgyi, A. (1934). Hoppe-Seyl. Z. 224, 1 .

Green, D. E. (1936). Biochem. J. 30, 2095.

Long, C. (1942). Biochem. J. 36, 807.

Long, C. (1943). Biochem. J. 37, 215.

Long, C., Ochoa, S. \& Peters, R. A. (1939). J. Physiol. 96, $7 P$.

\section{Properties of Azide-catalase}

\author{
By D. KEILIN AND E. F. HARTREE, Molteno Institute, University of Cambridge
}

\author{
(Received 8 January 1945)
}

It is now well established that catalase is a conjugated protein with protohaematin as its prosthetic or active group. Catalase resembles acid methaemoglobin in its colour, its absorption spectrum, and above all in its property of combining reversibly and forming well-defined derivatives with $\mathrm{HCN}$, $\mathrm{H}_{2} \mathrm{~S}, \mathrm{HN}_{3}, \mathrm{HF}, \mathrm{NH}_{2} \mathrm{OH}, \mathrm{NO}$ and $\mathrm{C}_{2} \mathrm{H}_{5} \mathrm{O} . \mathrm{OH}$. However, it differs from methaemoglobin in three important properties, namely: (1) the colour and absorption spectrum of its compound with azide $\left(\mathrm{NaN}_{3}\right),(2)$ the reaction with $\mathrm{H}_{2} \mathrm{O}_{2}$, which consists in a violent, almost explosive, decomposition of the latter, during which it is impossible to observe any changes in colour and absorption spectrum of the enzyme, and (3) the stability of its trivalent iron which is not reduced even by $\mathrm{Na}_{2} \mathrm{~S}_{2} \mathrm{O}_{4}$. In this latter respect catalase differs fundamentally from all other haematin derivatives (Keilin \& Hartree, 1936).

The main object of this investigation was to examine the properties of azide-catalase in the hope of gaining further insight into the mechanism of the reaction catalyzed by free catalase.

\section{MATERIALS AND METHODS}

Catalase used for this investigation was prepared from horse liver. The initial stages of extraction are based upon those of Zeile \& Hellström (1930). They have previously been described by us (Keilin \& Hartree, 1936, 1938), but we have since introduced slight modifications.

$5.5 \mathrm{~kg}$. liver is finely minced, mixed with an equal volume of tap water and allowed to stand overnight at $10-15^{\circ}$.
Next day, the fluid is pressed out and treated with $400 \mathrm{ml}$.* $90 \%$ ethanol/l. of fluid. The mixture is centrifuged for $30 \mathrm{~min}$. and the red-brown supernatant fluid again precipitated by the addition of $200 \mathrm{ml}$.* $90 \%$ ethanol plus $100 \mathrm{ml}$. chloroform $/ 1$. When the resulting precipitate is centrifuged down a clear yellow-brown fluid is obtained with a green fluorescence. Examination of a $3 \mathrm{~cm}$. layer with a small dispersion spectroscope should reveal the absorption band of catalase at $622 \mathrm{~m} \mu$. The fluid is left overnight at $5^{\circ}$ when a brown precipitate containing much inactive protein is deposited. This is filtered off to give about $4 \mathrm{l}$. of a clear green-brown solution. The enzyme was removed from this solution by shaking it with three successive lots of $200 \mathrm{ml}$. calcium phosphate gel (a suspension containing $1 \mathrm{~g}$. tricalcium phosphate $/ 40 \mathrm{ml}$.), the $\mathrm{pH}$ being maintained at $5 \cdot 6$ by means of acetic acid. The combined cakes of the gel were suspended in water, brought to $\mathrm{pH} 5 \cdot 6$ and centrifuged. The fluid was discarded and the catalase was eluted by suspending the gel in water, adjusting the $\mathrm{pH}$ to 8.0 with dilute ammonia and centrifuging. Two further extractions were made with $0.02 \mathrm{~N}$-ammonia. The combined eluates (790 ml.) were brought to $\mathrm{pH} \mathrm{5.5}$ and diluted to 11 . Addition of $250 \mathrm{~g}$. $\left(\mathrm{NH}_{4}\right)_{2} \mathrm{SO}_{4}$ yielded a precipitate of ferritin plus a little catalase. This was filtered off and the bulk of the catalase precipitated by addition of a further $100 \mathrm{~g}$. $\left(\mathrm{NH}_{4}\right)_{2} \mathrm{SO}_{4}$. This precipitate was filtered off, dissolved in $50 \mathrm{ml}$. water and electrodialyzed against running tap water to remove $\left(\mathrm{NH}_{4}\right)_{2} \mathrm{SO}_{4}$.

At this stage the catalase is pure enough for most purposes but can be purified further as follows: The solution is diluted to $250 \mathrm{ml}$. and treated with $50 \mathrm{ml}$. calcium phosphate gel at $\mathrm{pH} 7.0$ which is centrifuged off and discarded; it is then treated with $150 \mathrm{ml}$. calcium phosphate gel in three lots at $\mathrm{pH}$ 6.4. The-gel is centrifuged off, washed once with water and extracted five times with $0.025 \mathrm{M}-\mathrm{Na}_{2} \mathrm{HPO}_{4}$ (total

* The optimal volúmes of ethanol should be determined by preliminary small-scale experiments. 
volume of extract $450 \mathrm{ml}$.). This solution is treated with $\left(\mathrm{NH}_{4}\right)_{2} \mathrm{SO}_{4}(50 \mathrm{~g} . / 100 \mathrm{ml}$.), and the resulting precipitate is collected on a filter paper and electrodialyzed until salt-free. During the final electrodialysis the catalase often sediments to give a very concentrated solution at the bottom of the cell, depositing fine needle crystals of catalase on standing. The purity and activity of such crystals, however, do not differ from those of the mother liquor. Typical analyses of preparations obtained by this. method are given in Table 1 $(a-d)$.

The iron in these preparations was determined colorimetrically with $\alpha \alpha^{\prime}$-dipyridyl, and the haematin was determined spectroscopically as pyridine haemochromogen (Keilin \& Hartree, 1936).

\section{The activity of catalase preparations}

The activity (Kat. f.) of the enzyme, which represents the velocity constant $k$ of the reaction divided by the dry weight of the sample used for the estimation, was determined by a method based on that of Euler \& Josephson (1927) and Euler (1934). The value of the constant at zero time was determined by extrapolation from values determined at 3, 6 and 9 min. (Sumner, 1941).

Although no special attempt was made to purify our preparations by crystallization, their activities varied as a rule between 34,000 and 48,000.

These activities are higher than those obtained by Sumner \& Dounce (1937) for ox-liver catalase recrystallized several times $(26,000-43,000)$ or than those for crystalline horseliver catalase $(22,000-40,000)$ as given by Sumner, Dounce \& Frampton (1940), who showed also by diffusion experiments that two of their preparations were homogeneous. Our preparations were less active than those of Dounce \& Frampton (1939) or of Agner (1938, 1942), who give figures of $50,000-55,000$ and $59,000-61,000$ respectively, but attempts to confirm these values have not generally been successful (Sumner, 1941).

All liver catalase preparations contain a certain proportion of a bile pigment derivative which results from the oxidative fission of haematin groups which thereby become catalytically i nactive (Lemberg, Norrie \& Legge, 1939; Sumner, 1941). From the haematin content and the activity of catalase preparations one can calculate the activity of what can be described as 'complete catalase', i.e. a homogeneous protein free from bile pigment and containing four. haematin groups in each molecule. On the basis of a molecular weight $=240,000$ (Theorell \& Agner, 1942), the haematin content would be $1.08 \%$ corresponding to an iron content of $0.093 \%$. The figures obtained for the theoretical activity (Kat. f.) of 'complete catalase' (Table 1) are in good agreement and indicate that the total haematin in these preparations is present as the prosthetic group of the enzyme. This confirms our previous observations showing a strict parallelism between the intensities of the absorption bands and the haematin contents of various samples of catalase (Keilin \& Hartree, 1936). The calculated activity of our preparations per haematin group ( $d$, Table 1$)$ is intermediate between the values of 13,000 and 15,000 obtained by Lemberg \& Legge (1943) and by Sumner et al. (1940) respectively.
Table 1. Haematin content and activity of different catalase preparations

\begin{tabular}{|c|c|c|c|}
\hline & \multicolumn{3}{|c|}{ Catalase activity (Kat. f.) } \\
\hline $\begin{array}{l}\text { Haematin } \\
\text { (\% of } \\
\text { dry } \\
\text { weight }) \\
(a)\end{array}$ & $\begin{array}{l}\text { Found } \\
(b)\end{array}$ & $\begin{array}{l}\text { Calc. for } \\
\text { 'complete } \\
\text { catalase' } \\
\text { (c) }=\frac{b \times 1.08}{a}\end{array}$ & $\begin{array}{l}\text { Calc. } \\
\text { for one } \\
\text { haematin } \\
\text { group } \\
(d)= \pm d c\end{array}$ \\
\hline $\begin{array}{l}0.92 \\
0.92 \\
0.67\end{array}$ & $\begin{array}{l}48,000 \\
46,000 \\
34,000\end{array}$ & $\begin{array}{l}\mathbf{5 5 , 2 0 0} \\
\mathbf{5 4 , 0 0 0} \\
\mathbf{5 5 , 7 0 0}\end{array}$ & $\begin{array}{l}13,800 \\
13,500 \\
13,900\end{array}$ \\
\hline 0.72 & 36,000 & 54,000 & 13,500 \\
\hline
\end{tabular}

(mother liquor

from crystals)

\section{General properties of azide-catalase}

On addition of sodium azide to a catalase solution the colour of the solution becomes slightly more greenish, and the absorption band at $622 \mathrm{~m} \mu$ is intensified and moves about $2 \mathrm{~m} \mu$ nearer the blue end of the spectrum. Azide does not modify the general pattern of the absorption spectrum of catalase but only intensifies its main band in the red (Fig. 1): In this respect catalase differs markedly from methaemoglobin, which with azide forms a red compound with two bands at 575 and $542.5 \mathrm{~m} \mu$ (Keilin, 1936).

It can be shown spectroscopically that for the formation of azide-catalase one molecule of azide is required per molecule of haematin. The affinity of azide for catalase is, however, not as great as that of cyanide. Thus, if a solution of cyan-catalase containing two equivalents of cyanide to one of catalase haematin is treated with a standard azide solution, the absorption spectrum will indicate a $1: 1$ mixture of azide- and cyan-catalase only when 300 equivalents of azide are added to the solution. The affinity of cyanide for catalase is therefore 150 times greater than that of azide. Similar experiments carried out with fluoride and hydroxylamine in place of azide show that the relative affinities of these compounds for catalase at $\mathrm{pH} 7$ are approximately $\mathrm{KCN}: \mathrm{NaN}_{3}: \mathrm{NH}_{2} \mathrm{OH}: \mathrm{NaF}=10,000: 67: 40: 1$. The absorption spectra of catalase and its cyanide, azide and fluoride derivatives are shown in Fig. 1.

One of the most remarkable properties which azide-catalase shares with free catalase and with its cyan-, hydroxylamine- and fluoride-derivatives is its resistance to reducing agents. Not one of these compounds can be reduced even by such a powerful reducing agent as sodium hyposulphite $\left(\mathrm{Na}_{2} \mathrm{~S}_{2} \mathrm{O}_{4}\right)$. In this respect catalase differs from all known haematin derivatives. 


\section{Reaction of azide-catalase with peroxides}

We have shown previously (Keilin \& Hartree, 1936) that on addition of $\mathrm{H}_{2} \mathrm{O}_{2}$ or $\mathrm{BaO}_{2}$ to a strong solution of azide-catalase the colour of the solution turns from greenish brown to red and the characteristic absorption bands are replaced by two stronger bands at 587 and $559 \mathrm{~m} \mu$ (Fig. 1, V). In about by $\mathrm{CO}$ we deduced that peroxides reduce the iron of azide-catalase to the ferrous compound which can be oxidized by molecular oxygen to the original ferric azide-catalase. Hydroxylamine-catalase can also be reduced by peroxides to give a spectroscopically similar autoxidizable compound.

Theorell \& Agner (1942) confirmed our spectroscopic observations but offered an entirely different

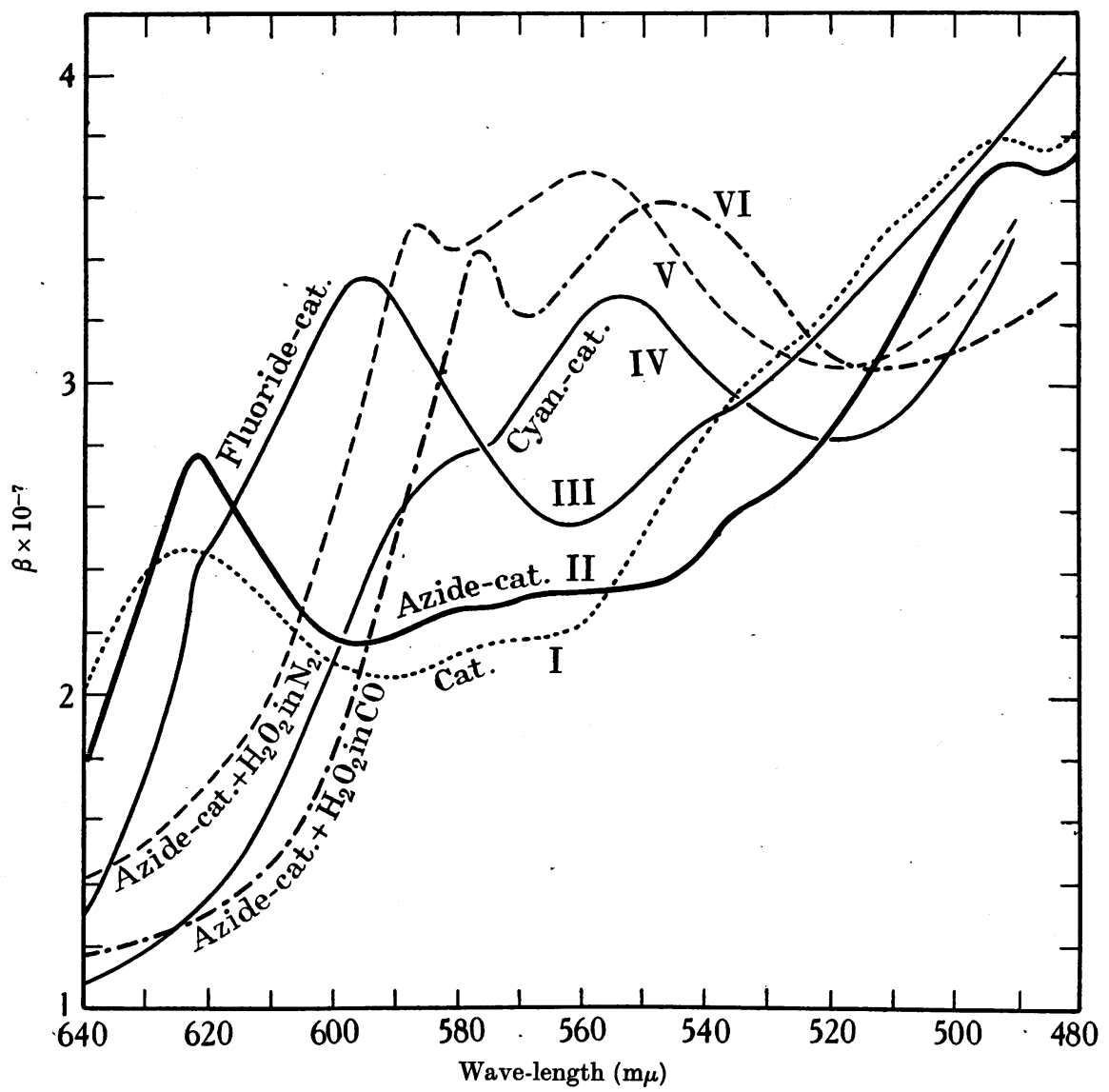

Fig. 1. Absorption spectra of catalase and its derivatives determined with the Hilger-Nutting spectrophotometer. $\beta=\frac{1}{c \times l} \log _{e} \frac{I_{0}}{I}$, where $c=$ concentration of catalase expressed as g.-mol. haematin $/ \mathrm{ml}$.; $l=$ depth of liquid layer in cm.; $I_{0}$ and $I=$ intensities of incident and transmitted light.

Curves: I, catalase ( $\mathrm{pH} \mathrm{6.8)}$; II, azide-catalase; III, fluoride-catalase; IV, cyan-catalase; V, azide-catalase $+\mathrm{H}_{2} \mathrm{O}_{2}$ in pure $\mathrm{N}_{2}$; VI, azide-catalase $+\mathrm{H}_{2} \mathrm{O}_{2}$ in $\mathrm{CO}$.

the presence of $\mathrm{CO}$ the two bands become more distinct and are slightly shifted towards the blue end of the spectrum. These two red compounds, especially the latter, are fairly stable in absence of oxygen, but in its presence they rapidly revert to the original azide-catalase. Even in absence of air, sufficient oxygen is liberated from the peroxide to bring about the change, though $\mathrm{CO}$ delays the latter considerably. From the change in spectrum brought interpretation. The red compound obtained by treating azide-catalase with hydrogen peroxide as well as its $\mathrm{CO}$ derivative are considered by them to contain iron in the trivalent state. This view, they believe, is supported by the following considerations:

(a) 'The azide superoxide compound in $\mathrm{N}_{2}$ shows a spectrum that so nearly resembles that of cyan-catalase that it is difficult to distinguish them' (Theorell \& Agner, 1942, p. 8). 
(b) Magnetic susceptibility values for azide-catalase treated with $\mathrm{BaO}_{2}$ in $\mathrm{N}_{2}$ or in $\mathrm{CO}$ are of the same order as those obtained for the cyanide and sulphide derivatives of catalase and are therefore incompatible with the view that these compounds contain ferrous iron.

(c) It is difficult to understand how azide could inhibit the oxidation of ferrohaem since 'no ferrohaemin-azide proteids are definitely known with the possible exception of verdoperoxidase' which was described by Agner (1941).

We shall now examine in detail these three considerations brought forward by Theorell \& Agner.

(a) Spectroscopic evidence. We cannot agree with the statement that the absorption spectrum of azidecatalase treated with peroxide is indistinguishable from that of cyan-catalase. In fact, even when examined with a small dispersion spectroscope the absorption spectra of these two compounds appear to be different. Reference to the absolute absorption spectra (Fig. 1, IV and V) settles the point beyond dispute.

The absorption spectrum of azide-catalase treated with peroxide was determined in $\mathrm{N}_{2}$ by using a Thunberg tube to the end of which was fused a $2 \mathrm{~cm}$. cell with optical glass end plates. Hydrogen peroxide was added from the hollow stopper after filling the tube with $\mathrm{N}_{2}$. The CO derivative was measured in the same tube in an atmosphere of $\mathrm{CO}$ when the shift of the bands was easily demonstrated (Fig. 1, V and VI). The spectrophotometric curves thus obtained clearly show the marked differences between the absorption spectrum of cyan-catalase and that of azide-catalase treated with peroxide in absence of oxygen.

(b) Evidence from magnetic susceptibility. In coordination compounds of iron the linkages may be either essentially ionic or essentially covalent independently of the valency of the iron (Pauling, 1942). With solutions containing a high concentration of haematin measurements are sufficiently precise to allow a clear indication of the valency of the iron to be obtained (Pauling \& Coryell, 1936a), but with haemoglobin there may be deviations from the theoretical figures on account of interaction between haematin groups (Pauling \& Coryell, 1936b). In the case of catalase and its derivatives the possibility of such interaction remains, while a further uncertainty arises from the fact that the purest liver catalase contains less than $1 \%$ haematin and the magnetic contribution of the rest of the molecule, which also contains iron in a variable amount, is difficult to assess.

The view of Theorell \& Agner (1942) that azidecatalase treated with $\mathrm{H}_{2} \mathrm{O}_{2}$ in $\mathrm{N}_{2}$ or in $\mathrm{CO}$ gives rise to ferric derivatives is based upon the fact that their values of the magnetic susceptibilities of these derivatives are of the same order as those of cyan- or sulphide-catalase, the ferric nature of which can be established independently. The validity of this interpretation, however, rests upon the assumption that the compound formed when azide-catalase reacts with $\mathrm{H}_{2} \mathrm{O}_{2}$ remains unchanged during the experiment. We have shown that even in purified $\mathrm{N}_{2}$ the ferrous azide-catalase will undergo oxidation by $\mathrm{O}_{2}$ liberated from $\mathrm{H}_{2} \mathrm{O}_{2}$ giving 25 and $50 \%$ of ferric azide-catalase within 90 and $110 \mathrm{~min}$. respectively. This change is much more rapid in contact with air, and a partial oxidation can scarcely be avoided in the manipulations described by Theorell \& Agner which involve transfer of the labile reduced compound from a Thunberg tube to a long open capillary suspended in a magnetic field. Under these conditions atmospheric $\mathrm{O}_{2}$, and $\mathrm{O}_{2}$ liberated from $\mathrm{H}_{2} \mathrm{O}_{2}$ owing to its contact with a much larger area of glass and with a celluloid septum, will accelerate the reoxidation of ferrous azide-catalase.

Theorell \& Agner found the molar magnetic susceptibility of ferric azide-catalase, $\chi_{m}$, to be 14,500 $\times 10^{-6}$. They calculate the value for ferrous azidecatalase to be $\leqq 3700 \times 10^{-6}$ assuming it contains 3 ferrohaems with covalent bonds (no unpaired electrons) and 1 ferric atom attached to bile-pigment by ionic bonds ( 5 unpaired electrons). Their values of $6600 \times 10^{-6}$ and $4920 \times 10^{-6}$ for azide-catalase treated with $\mathrm{BaO}_{2}$ in $\mathrm{N}_{2}$ and in $\mathrm{CO}$ respectively can be accounted for if we assume that $25 \%$ of the reduced azide-catalase in $\mathrm{N}_{2}$ and $19 \%$ of its $\mathrm{CO}$ derivative were oxidized to the ferric state as a result of the preliminary manipulations.

Moreover, the low concentration of haematin iron in preparations of pure catalase $(<0.093 \%)$ necessitates the use of highly concentrated catalase solutions which in the experiments of Theorell \& Agner contained $8 \cdot 4-18.9 \%$ of pure crystalline catalase. At such concentrations it becomes difficult to suppress entirely the catalytic activity of the enzyme by azide. It is therefore difficult to avoid the formation of minute bubbles of oxygen, the paramagnetism of which may cause unpredictable changes in the values of the magnetic susceptibilities of the enzyme solutions.

We can say in conclusion that whereas the instability of the compound obtained by treating azidecatalase with $\mathrm{H}_{2} \mathrm{O}_{2}$ invalidates any determination of the valency of its iron by magnetic measurements, its reactions with $\mathrm{O}_{2}$ and with $\mathrm{CO}$ clearly demonstrate that this compound contains ferrous iron.

(c) Evidence based on the reaction of azide with other haematin compounds. The fact that azide does not react with haemoglobin $\left(\mathrm{Fe}^{++}\right)$although it combines with methaemoglobin $\left(\mathrm{Fe}^{+++}\right)$cannot be generalized into a statement that azide reacts solely with ferric haematin derivatives and that therefore the existence of ferrous azide-catalase is improbable. In fact, although azide combines with methaemoglobin it fails to react with the ferric derivatives of haematin, parahaematin and oxidized cytochrome. It must also be remembered that the addition of azide to methaemoglobin drastically changes its 
colour and absorption spectrum, yet it only slightly modifies the colour and absorption spectrum of catalase. Whereas in azide-methaemoglobin the iron atoms are bound by essentially covalent bonds (Coryell, 1939), in azide-catalase the linkages are ionic (Theorell \& Agner, 1942).

The danger of generalizations of certain properties of haematin derivatives can be well illustrated by their reactions with cyanide. As is well known, cyanide forms a definite compound with methaemoglobin $\left(\mathrm{Fe}^{+++}\right)$and although it does not combine with haemoglobin $\left(\mathrm{Fe}^{++}\right)$it does react both with haematin $\left(\mathrm{Fe}^{+++}\right)$and with haem $\left(\mathrm{Fe}^{++}\right)$. Moreover, within the physiological range of $\mathrm{pH}$ it fails to react with components $a, b$ and $c$ of cytochrome but does combine both with ferric and ferrous forms of cytochrome oxidase or the component $a_{3}$ (Keilin \& Hartree, 1939).

(d) Additional evidence and conclusions. Two further indications of the reduction of azide-catalase by peroxide can be obtained by comparing the effects of different catalase inhibitors. (1) Although the affinity of cyanide for ferric catalase is about 150 times greater than that of azide, the addition of cyanide to azide-catalase previously treated with $\mathrm{H}_{2} \mathrm{O}_{2}$ in an atmosphere of pure $\mathrm{N}_{2}$ does not cause any change in the spectrum of the ferrous azidecatalase. The $\alpha$-band of this compound remains sharper than the $\beta$-band, in contrast to the cyancatalase spectrum, in which the $\alpha$-band is comparatively feeble. On replacing $\mathrm{N}_{2}$ by $\mathrm{CO}$ the absorption bands shift towards the blue end of the spectrum as the CO derivative is formed. (2) The affinities of azide and hydroxylamine for ferric catalase are respectively 150 and 250 times lower than that of cyanide and yet azide and hydroxylamine are stronger inhibitors of the catalase reactions than is cyanide. This is readily explained on the assumption that cyanide reacts only with ferric catalase while azide and hydroxylamine react with both ferric and ferrous forms. The strong inhibiting action of azide and of hydroxylamine is explicable as the result of the stabilization of the ferrous state by these substances, the oxidation to ferric iron thus being greatly delayed.

The relative inhibitory effects of azide, hydroxylamine and cyanide were estimated from the concentrations of these substances necessary to inhibit by $50 \%$ the rate of decomposition of $\mathrm{H}_{2} \mathrm{O}_{2}$ by catalase.

The experiments were carried out in Barcroft differential manometers at $18^{\circ}$ under the experimental conditions described on p. 154 except that $0.03 \mathrm{M}-\mathrm{KH}_{2} \mathrm{PO}_{4}$ was replaced by phosphate buffer $\mathrm{pH} 6.8$ of the same concentration. A strong catalase solution was diluted and $.0 .2 \mathrm{ml}$. taken for each manometer giving a haematin concentration of $2 \times 10^{-9} \mathrm{M}$. The effect of varying concentrations of the three inhibitors on the initial rate of decomposition of $0.3 \mathrm{ml}$. $\mathrm{H}_{2} \mathrm{O}_{2}$ ( $\equiv 300 \mu$ l. $\mathrm{O}_{2}$ ) was determined and the concentration required to give $50 \%$ inhibition was read off after plotting the results in the form: \% inhibition against log concentration of inhibitor. Separate large-scale experiments showed that under these conditions $\ngtr 5 \%$ of the cyanide was in the gas space as HCN. The experimental results are summarized in Table 2.

Table 2. Inhibition of catalase activity by azide, hydroxylamine and cyanide, and the relative affinity of these substances for the enzyme

$\begin{array}{lcc}\text { Molarity to give } & \begin{array}{c}\text { Relative affinity } \\ \text { for ferric catalase } \\ \text { Inhibitor }\end{array} & 50 \% \text { inhibition } \\ \mathrm{NaN}_{3} & 6 \cdot 3 \times 10^{-8} & 67 \\ \mathrm{NH}_{2} \mathrm{OH} & 6.3 \times 10^{-7} & 40 \\ \mathrm{KCN} & 4.3 \times 10^{-6} & 10,000\end{array}$

From the evidence brought forward it is clear that, on treatment with $\mathrm{H}_{2} \mathrm{O}_{2}$, ferric azide-catalase undergoes reduction, thus yielding a ferrous compound. The latter shares with other ferrous haematin derivatives the properties: (1) of being stable only in absence of oxygen, (2) of undergoing a very rapid autoxidation in presence of molecular oxygen, and (3) of forming with $\mathrm{CO}$ a compound which is fairly resistant to oxygen. In this respect it must be remembered that there is not a single case reported of a haematin derivative combining with $\mathrm{CO}$ in the ferric state.

Our conclusion is strongly supported by the spectroscopic study of azide-catalase and its derivatives, and is not in the least contradicted by the measurements of magnetic susceptibilities of these compounds carried out by Theorell \& Agner. Moreover, several statements in the paper by these workers actually support our view. They notice that 'the change in the position of the bands found by Keilin \& Hartree when azide-catalase-superoxide is formed in CO speaks, certainly, strongly in favour of ferro-haemin'. They also report that 'the CO compound seems to be less sensitive to the effect of oxygen than the compound that is formed in $\mathrm{N}_{2}$ '. In carrying out measurements of the magnetic susceptibility Theorell \& Agner found it necessary to protect from oxygen the azide-catalase treated with $\mathrm{BaO}_{2}$. We fail to see why this should be necessary if the iron in the red compound thus obtained is, as they believe, in the trivalent state and there is no other part of the molecule which can undergo a reversible autoxidātion.

$$
\text { Azide-catalase as a reagent for } \mathrm{H}_{2} \mathrm{O}_{2}
$$

Azide-catalase is certainly one of the most sensitive reagents for the detection of $\mathrm{H}_{2} \mathrm{O}_{2}$ formed by reduction of molecular oxygen during catalytic oxidations and autoxidations of different substances.

We have carried out these reactions in glass tubes $20 \mathrm{~mm}$. high $\times 9 \mathrm{~mm}$. diameter with fused-on optical end-plates. These tubes are placed on a microscope stage over the con- 
denser and observations are carried out with the microspectroscope ocular. Sufficient catalase solution (0.2$0.5 \mathrm{ml}$.) is added to the tube to render the absorption band at $622 \mathrm{~m} \mu$. clearly visible. $0.1 \mathrm{ml}$. 0.1 M-phosphate buffer pH 6.8 and $5 \mathrm{mg}$. sodium azide are added when the azide compound is formed as indicated by the shift and intensification of the main absorption band. A piece of glass tubing is drawn out and bent so that it can be introduced into the tube to aerate the contents. A trace of caprylic alcohol is added to avoid frothing.

(1) Detection of the $\mathrm{H}_{2} \mathrm{O}_{2}$ formed in the glucose oxidase glucose system. If to the azide-catalase is added $0.1 \mathrm{ml}$. of a very active glucose oxidase* and $0.1 \mathrm{ml} .5 \%$ glucose, the colour and absorption spectrum of the solution remain unchanged. On passing a fine stream of air through this mixture its colour becomes distinctly red and spectroscopic observation shows the formation of ferrous azide-catalase indistinguishable from the compound formed on adding $\mathrm{H}_{2} \mathrm{O}_{2}$ to azide-catalase. When the air current is stopped the solution rapidly reverts to the original greenish colour of azide-catalase and shows the characteristic absorption band. If $\mathrm{CO}$ is present during the experiment it combines with the ferrous azide-catalase as already described. The formation of $\mathrm{H}_{2} \mathrm{O}_{2}$ during the aerobic oxidation of glucose to gluconic acid catalyzed by glucose oxidase is thus clearly demonstrated spectroscopically. In the same way the formation of $\mathrm{H}_{2} \mathrm{O}_{2}$ can be detected when the enzymes xanthine oxidase, $d$-amino-acid oxidase and uricase catalyze the aerobic oxidation of their respective substrates in presence of azide-catalase.

(2) Detection of $\mathrm{H}_{2} \mathrm{O}_{2}$ during the autoxidation of sodium hyposulphite $\left(\mathrm{Na}_{2} \mathrm{~S}_{2} \mathrm{O}_{4}\right)$. The same method permits the detection of $\mathrm{H}_{2} \mathrm{O}_{2}$ during the autoxidation of $\mathrm{Na}_{2} \mathrm{~S}_{2} \mathrm{O}_{4}$. As the trivalent iron of azide-catalase, like that of catalase, cannot be reduced by this reagent, no changes are observed when azide-catalase is treated with about $5 \mathrm{mg}$. of the reagent under the conditions just described. On passing a stream of air, however, the formation of ferrous azidecatalase is at once apparent, but it persists only as long as the air stream is maintained or until the $\mathrm{Na}_{2} \mathrm{~S}_{2} \mathrm{O}_{4}$ is completely oxidized. To prevent the solution becoming too acid it is better to use disodium phosphate instead of a neutral buffer. In presence of $\mathrm{CO}$ the-CO-derivative is rapidly formed.

\section{Reduction of trivalent iron by $\mathrm{H}_{2} \mathrm{O}_{2}$}

The reduction of the ferric iron of azide-catalase by $\mathrm{H}_{2} \mathrm{O}_{2}$ is not without parallel in the chemical behaviour of $\mathrm{H}_{2} \mathrm{O}_{2}$ which under certain conditions may act as a reducing agent. Kuhn \& Wassermann (1933) showed that in presence of $\alpha \alpha^{\prime}$-dipyridyl ferric salts are quantitatively reduced by $\mathrm{H}_{2} \mathrm{O}_{2}$ to the ferrous dipyridyl complex. This reaction may be demonstrated very simply by the addition of $\mathrm{H}_{2} \mathrm{O}_{2}$ to a solution of ferric chloride in presence of $\alpha \alpha^{\prime}$. dipyridyl. It was therefore of interest to find whether haematin derivatives other than azidecatalase could be reduced by $\mathrm{H}_{2} \mathrm{O}_{2}$.

* A sample of purified glucose oxidase (notatin) used in these experiments was kindly supplied by Prof. H. Raistrick and $\operatorname{Dr}$ J. H. Birkinshaw.
(1) Reduction of alkaline methaemoglobin by $\mathrm{H}_{2} \mathrm{O}_{2}$. Acid methaemoglobin, as we have shown previously, forms a definite compound with $\mathrm{H}_{2} \mathrm{O}_{2}$ but the iron of this derivative remains in the trivalent state (Keilin \& Hartree, 1935) even in complete absence of $\mathrm{O}_{2}$ or in presence of $\mathrm{CO}$. Although it decomposes rapidly on standing, no recognizable ferrous derivatives can be detected. It is possible, however, at a higher $\mathrm{pH}$ to observe reduction of methaemoglobin iron.

For this purpose a catalase-free solution of methaemoglobin was prepared from recrystallized oxyhaemoglobin. It was diluted with $0.25 \mathrm{M}-\mathrm{Na}_{2} \mathrm{HPO}_{4}$ until it contained $14 \mathrm{mg}$. protein $/ \mathrm{ml}$. About $3 \mathrm{ml}$. of this solution are placed in a Thunberg tube and $0.1 \mathrm{ml} .20 \mathrm{vol} . \mathrm{H}_{2} \mathrm{O}_{2}$ placed in the hollow stopper. The tube is filled with $\mathrm{CO}$ by evacuation, closed and inverted. Spectroscopic examination of this solution shows that the absorption bands of alkaline methaemoglobin are gradually replaced by those of COhaemoglobin. In other words, the trivalent iron has been reduced by $\mathrm{H}_{2} \mathrm{O}_{2}$. In a similar experiment at $\mathrm{pH} \mathrm{6.8} \mathrm{the}$ addition of $\mathrm{H}_{2} \mathrm{O}_{2}$ yielded a mixture of free acid methaemoglobin and its $\mathrm{H}_{2} \mathrm{O}_{2}$ compound. During $15 \mathrm{~min}$. standing, complex changes took place but faint bands of CO-haemoglobin could be detected. Lemberg, Legge \& Lockwood (1941) have also given evidence for the reduction of methaemoglobin by $\mathrm{H}_{2} \mathrm{O}_{2}$.

(2) Reduction of ferric cytochrome c by $\mathrm{H}_{2} \mathrm{O}_{2}$. A solution of ferric cytochrome $c$ in disodium phosphate is slowly reduced to the ferrous form by very dilute $\mathrm{H}_{2} \mathrm{O}_{2}$.

This can be easily demonstrated by treating $5 \mathrm{ml} .0 \cdot 1 \%$ oxidized cytochrome $c$ in $0.2 \mathrm{M}-\mathrm{Na}_{2} \mathrm{HPO}_{4}$ with $0.1 \mathrm{ml} . \mathrm{H}_{2} \mathrm{O}_{2}$ $\left(\equiv 100 \mu \mathrm{l} . \mathrm{O}_{2}\right.$ ). Within $5 \mathrm{~min}$. the sharp $\alpha$-band of reduced cytochrome $c$ can be seen superimposed upon the diffuse absorption band of oxidized $c$. The band eventually fades as cytochrome undergoes a destructive oxidation. This experiment may be carried out in an open tube since reduced cytochrome $c$ is not autoxidizable below $\mathrm{pH} 12$.

\section{Other attempts to reduce the trivalent iron of catalase}

Zeile, Fawaz \& Ellis (1940) claimed that they were able to reduce $\mathrm{H}_{2} \mathrm{~S}$-catalase by treating it with $\mathrm{Na}_{2} \mathrm{~S}_{2} \mathrm{O}_{4}$ and removing $\mathrm{H}_{2} \mathrm{~S}$ by means of a stream of $\mathrm{N}_{2}$. The solution thus obtained was described as showing no distinct absorption bands, but when this solution was shaken with air the absorption spectrum of the original catalase returned. We attempted several times to repeat these experiments but failed to obtain the above results.

More recently Dounce \& Howland (1943) claimed that from a crystalline beef-liver catalase dried in a frozen state they obtained a preparation which could be reversibly reduced with $\mathrm{Na}_{2} \mathrm{~S}_{2} \mathrm{O}_{4}$. They concluded that drying catalase in a frozen state causes 'a mild denaturation' and 'a sufficient loosening of the linkage between iron and protein to permit $\mathrm{Na}_{2} \mathrm{~S}_{2} \mathrm{O}_{4}$ to reduce the iron'. The activity of this preparation was, however, only one-third 
that of the original preparation. The similarity of the spectrophotometric curves of original and dried catalase shows only that the latter contains an undetermined amount of unmodified catalase, since absolute values for the extinction coefficient have not been used by these workers in plotting the absorption curves. The dried preparation was probably a mixture of about one-third unmodified and fully active catalase and two-thirds of a modified and completely inactive enzyme responsible for the change in absorption spectrum on reduction. The properties of such a preparation can hardly throw any light on the mechanism of decomposition of $\mathrm{H}_{2} \mathrm{O}_{2}$ by catalase.

\section{Manometric experiments demonstrating the reduction of azide-catalase by $\mathrm{H}_{2} \mathrm{O}_{2}$}

Spectroscopic experiments have clearly shown that azide-catalase is reduced by $\mathrm{H}_{2} \mathrm{O}_{2}$ to an autoxidizable ferrous compound. The inhibition of catalase activity by azide is therefore due to the stabilization of the ferrous state of the enzyme just as cyanide inhibition is due to the stabilization of the ferric state. As we have shown, the stability of ferrous azide-catalase is greater in $\mathrm{N}_{2}$, and much greater in $\mathrm{CO}$, than in air. The problem that arises is whether $\mathrm{CO}$, by stabilizing the ferrous form, will inhibit the activity of catalase in presence of concentrations of azide which are in themselves too low to have a marked inhibitory effect. Although a brief answer to the question has already been given (Keilin \& Hartree, 1938) we considered it important to repeat this work over a wider range of experimental conditions.

The experiments were carried out in Barcroft differential manometers at room temperature. The right flasks received $0.3-0.5 \mathrm{ml}$. of very dilute catalase, $0.3 \mathrm{ml}$. sodium azide solution of suitable concentration and $0.03 \mathrm{M}-\mathrm{KH}_{2} \mathrm{PO}_{4}$ to bring the volume to $3.0 \mathrm{ml}$. In a dangling tube was placed $0.3 \mathrm{ml}$. $\mathrm{H}_{2} \mathrm{O}_{2}$ (equiv. $300 \mu \mathrm{l}$. $\mathrm{O}_{2}$; diluted perhydrol). $\mathrm{By}$ using glassware freshly cleaned with chromic acid and thoroughly rinsed, the spontaneous decomposition of $\mathrm{H}_{2} \mathrm{O}_{2}$ was found to be negligible. The left flasks received $3.3 \mathrm{ml}$. $0.03 \mathrm{M}-\mathrm{KH}_{2} \mathrm{PO}_{4}$. Gases were introduced into the manometers, while they were shaking, by evacuating three times to about $50 \mathrm{~mm}$. $\mathrm{Hg}$ and allowing the gas to stream in slowly: $\mathrm{N}_{2}$ and $\mathrm{CO}$ were freed from oxygen by passing them over copper heated to $400^{\circ}$. A mercury gasometer was used for storing the oxygen-free $\mathrm{CO}$ and for making up $\mathrm{CO}: \mathrm{N}_{2}$ mixtures. Gas stored in the gasometer sometimes picked up impurities capable of inhibiting free catalase, and it was therefore passed to the manometers via a charcoal trap. The $\mathrm{CO}: \mathrm{O}_{2}$ mixtures were made up over water. After introduction of the gases and equilibration of temperature the manometer taps were closed, the dangling tubes dislodged and the manometers shaken rapidly (200 strokes/min.). Readings were taken every $\mathrm{min}$. for $10 \mathrm{~min}$. The initial, almost constant, rate of $\mathrm{O}_{2}$ evolution was recorded. The small concentrations of azide used exerted only a small inhibition (c. $25 \%$ ) on the catalase.

(a) The inhibition of catalase activity by $\mathrm{CO}$ in presence of varying concentrations of azide. The right flasks of the manometers received $0.4 \mathrm{ml}$. catalase diluted 10,000 times (about $1.9 \times 10^{-8} \mathrm{M}$ in haematin). A pair of experiments, one in pure $\mathrm{N}_{2}$ and one in $\mathrm{CO}$, was carried out in presence of each of seven concentrations of sodium azide varying from 0 to $3 \times 10^{-8} \mathrm{M}$. Under these conditions azide-free catalase was inhibited neither by $\mathrm{N}_{2}$ nor by $\mathrm{CO}$, when compared with air as a standard. The results of these experiments, which are summarized in Fig. 2, show that CO inhibits the activity of the

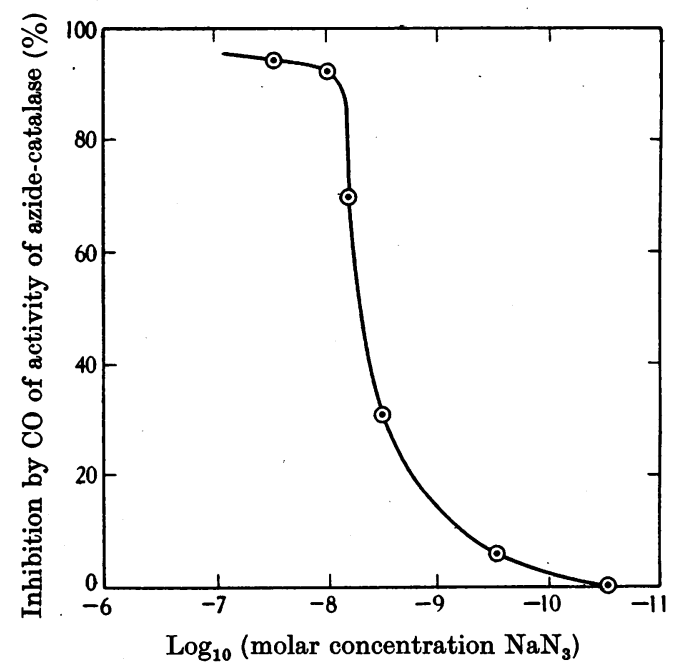

Fig. 2. Inhibitory effect of $\mathrm{CO}$ on the decomposition of $\mathrm{H}_{2} \mathrm{O}_{2}$ by azide-catalase. The influence is indicated of varying concentrations of sodium azide on the inhibitory action of $\mathrm{CO}$ compared with pure $\mathrm{N}_{2}$ as standard. Catalase haematin, $1.86 \times 10^{-8} \mathrm{M}$.

enzyme by more than $90 \%$ at azide concentration reaching $10^{-8} \mathrm{M}$, which corresponds to about half the calculated concentration of catalase haematin present at the beginning of the experiment. The fragility of the very dilute catalase in the flask, which increases markedly in presence of $\mathrm{CO}$, may certainly account for a destruction of $50 \%$ of the catalase during the preliminary manipulations. In this case the position of the inflexion of the curve indicates the presence of azide and catalase components in a $1: 1$ ratio.

(b) The activity of azide-catalase in $\mathrm{CO}: \mathrm{O}_{2}$ and $\mathrm{CO}: \mathrm{N}_{2}$ mixtures. In these experiments a more concentrated solution of catalase was used (approximately $4 \times 10^{-7} \mathrm{M}$ in haematin) together with $10^{-6} \mathrm{M}$ sodium azide. The percentage inhibition of enzyme activity in $\mathrm{CO}: \mathrm{N}_{2}$ mixtures was estimated by comparison with the activity of a control experiment in 
$\mathrm{N}_{2}$,* whereas the activity in $\mathrm{CO}: \mathrm{O}_{2}$ mixtures was compared with that in the corresponding $\mathrm{N}_{2}: \mathrm{O}_{2}$ mixtures. The enzyme activity in all control experiments showed no appreciable variations. The rate of decomposition of $\mathrm{H}_{2} \mathrm{O}_{2}$ was measured over a period of $1 \mathrm{~min}$. because with a shorter period consistent results could not be obtained, while longer periods would introduce progressively larger changes in the composition of the gas phase. The experimental results are summarized in Fig. 3 (I, II). The

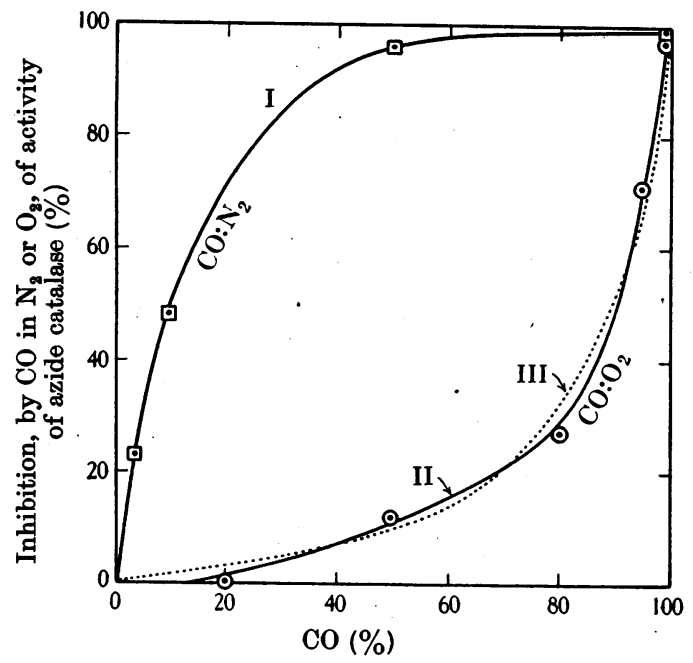

Fig. 3. Inhibitory effect of $\mathrm{CO}$ on the decomposition of $\mathrm{H}_{2} \mathrm{O}_{2}$ by azide-catalase. $4 \times 10^{-7} \mathrm{M}$-catalase haematin and $10^{-6} \mathrm{M}$-sodium azide. Effect of: (I) $\mathrm{CO}: \mathrm{N}_{2}$ compared with $\mathrm{N}_{2}$; (II) CO: $\mathrm{O}_{2}$ compared with $\mathrm{N}_{2}: \mathrm{O}_{2}$; (III) theoretical curve for $\mathrm{CO}: \mathrm{O}_{2}$ mixtures, assuming the partition constant $k=9$.

curve for $\mathrm{CO}: \mathrm{N}_{2}$ mixtures is in fact a curve for these mixtures plus the quantity of $\mathrm{O}_{2}$ produced during 1 min. Curve I will therefore occupy a position intermediate between curve II and a theoretical curve of inhibitions at zero time. The deviation of I from such a theoretical curve will increase with the rate of liberation of oxygen and therefore will be greatest when the percentage inhibition is smallest (i.e. in small partial pressure of CO). We may there-

* Under these conditions the catalytic activities in air and $\mathrm{N}_{2}$ are identical, although the spectroscopic experiments lead us to expect an inhibition in $\mathrm{N}_{2}$. However, the ratio (catalase) $/\left(\mathrm{H}_{2} \mathrm{O}_{2}\right)$ is $20,000-50,000$ times higher in the spectroscopic than in the manometric experiments. One can therefore expect differences of a similar order of magnitude in theratio (rate of $\mathrm{O}_{2}$ production)/(catalase iron), and when this ratio is high the chances of stabilizing an autoxidizable ferrous form in $\mathrm{N}_{2}$ become remote. By using $0.5 \mathrm{ml}$. undiluted catalase and $\mathbf{0 . 3} \mathrm{M}$-azide in Barcroft manometers the conditions are closer to those of the spectroscopic experiments and, under these circumstances, about $50 \%$ inhibition in $\mathrm{N}_{2}$ can be obtained. fore postulate that the theoretical $\mathrm{CO}: \mathrm{N}_{2}$ curve will correspond to a virtually complete inhibition of the reaction for all $\mathrm{CO}: \mathrm{N}_{2}$ ratios, whereas the position of $I$ is variable, depending upon the time interval over which the decomposition of $\mathrm{H}_{2} \mathrm{O}_{2}$ is measured. Curve II for $\mathrm{CO}: \mathrm{O}_{2}$ mixtures, on the other hand, may be considered as significant, as the rate of $\mathrm{O}_{2}$ production will not appreciably alter the $\mathrm{CO}: \mathrm{O}_{2}$ ratio except at vanishingly small $\mathrm{O}_{2}$ pressures. In $\mathrm{CO}: \mathrm{O}_{2}$ mixtures there is a definite competition between the two gases for the ferrous azide-catalase, the enzyme having a greater affinity for $\mathrm{O}_{2}$ than for CO. The partition constant of azide-catalase between $\mathrm{O}_{2}$ and $\mathrm{CO}$ can be expressed as

$$
k=\frac{\left[\text { Cat. } \mathrm{O}_{2}\right][\mathrm{CO}]}{[\text { Cat. } \mathrm{CO}]\left[\mathrm{O}_{2}\right]},
$$

where Cat. $\mathrm{O}_{2}$ and Cat. $\mathrm{CO}$ denote the concentration of active and inactivated enzyme respectively. The value of $k$ for the preparation examined is approximately 9 (III, Fig. 3) and hence of the same order as $k$ for cytochrome oxidase (Keilin, 1930). However, as this result was based only upon two sets of experiments the possibility of a variation in the vadue of $k$ according to experimental conditions cannot be overlooked. It is important to note that the portion of the enzyme inhibited by $\mathrm{CO}$ may comprise two fractions: one reversibly and the other irreversibly inactivated. The irreversible inhibition may be due to the fact that the stabilizing of the azide-catalase in the ferrous state makes its porphyrin rings more fragile and so more liable to undergo oxidative fission by $\mathrm{H}_{2} \mathrm{O}_{2}$ (Lemberg et al. 1941). However, we have been able to confirm our previous experiments showing that the inhibition of azide-catalase by $\mathrm{CO}$ is to a great extent restored by the radiation from a mercury vapour lamp. Thus the irreversible inhibition by $\mathrm{CO}$ can occur to a small extent only.

We have carried out a large number of manometric experiments in phosphate buffer, $\mathrm{pH} 6.8$, with results similar in every way to those already 'described. We have also obtained analogous results using hydroxylamine in place of azide.

\section{DISCUSSION}

Although catalase can be easily purified and obtained in a concentration suitable for direct spectroscopic examination, the great difficulty in the study of the mechanism of its reaction with $\mathrm{H}_{2} \mathrm{O}_{2}$ is the violent decomposition of the latter unaccompanied by any visible change in the colour or absorption spectrum of the enzyme.

If an intermediate compound is formed in this reaction, it must have much too short a life to be detected spectroscopically. It is only by considerably slowing down the velocity of the reaction that 
one could hope to detect such an intermediate com. pound. This can be achieved by studying the reaction in the presence of certain inhibitors. It has been found that whereas the inhibition of the catalase reaction by cyanide and sulphide is due to the stabilization of the trivalent iron of catalase, thus preventing the formation of an intermediate compound, the inhibition by azide or by hydroxylamine is due to the stabilization of an intermediate ferrous compound of catalase, thus inhibiting its reoxidation to the original ferric state. The compound which is obtained by treating azide-catalase with $\mathrm{H}_{2} \mathrm{O}_{2}$ shares with ferrous haematin derivatives the property of being autoxidizable and of combining with $\mathrm{CO}$.

Considering that the combination of catalase with azide is perfectly reversible and that azide-catalase has many properties in common with free catalase (such as colour, absorption spectrum, magnetic susceptibility and resistance to reducing agents), it would appear that the reaction of azide-catalase with $\mathrm{H}_{2} \mathrm{O}_{2}$ is the best model reaction for the study of the mechanism of the catalytic decomposition of $\mathrm{H}_{2} \mathrm{O}_{2}$ by free catalase.

The fact that ferric azide-catalase can be reduced by peroxide to a ferrous compound which can be reoxidized by molecular oxygen suggested that the catalytic activity of the free catalase is based upon similar reactions. The two equations which we proposed in a previous paper (Keilin \& Hartree, 1938):

$$
\begin{aligned}
4 \mathrm{Fe}^{+++}+2 \mathrm{H}_{2} \mathrm{O}_{2} & =4 \mathrm{Fe}^{++}+4 \mathrm{H}^{+}+2 \mathrm{O}_{2}, \\
\frac{4 \mathrm{Fe}^{++}+\mathrm{O}_{2}+4 \mathrm{H}^{+}}{}=4 \mathrm{Fe}^{+++}+2 \mathrm{H}_{2} \mathrm{O} & \\
2 \mathrm{H}_{2} \mathrm{O}_{2} & =2 \mathrm{H}_{2} \mathrm{O}+\mathrm{O}_{2}
\end{aligned}
$$

are nothing more than a general outline of the over-all reaction experimentally demonstrated for azide-catalase, involving (1) changes of valency of catalase iron and (2) oxidation of the ferrous catalase by molecular oxygen. Any other equations adequately expressing these two facts would be equally acceptable.

The view that the catalytic activity of free catalase is accompanied by changes in the valency of its iron has already been suggested by other workers (Haber \& Willstätter, 1931; Weiss, 1937).

However, the failure to demonstrate manometrically for the free catalase the importance of oxygen in this reaction is not surprising if the affinity of ferrous catalase for oxygen is very great.* It is conceivable that even in an atmosphere of nitrogen

\footnotetext{
* Our previous experiments, in which we believed to have demonstrated manometrically the part played by oxygen in this reaction, could not be confirmed. As we have recently shown (Keilin \& Hartree, 1943), the depression of the catalytic activity of the free enzyme was due in these cases not to the absence of oxygen but to the presence of minute traces of oxides of nitrogen formed by passing the nitrogen over hot copper at a temperature well above $400^{\circ}$.
}

sufficient oxygen will be available either from the spontaneous decomposition of the $\mathrm{H}_{2} \mathrm{O}_{2}$ or from the initial reduction of ferric iron (reaction 1) to initiate the catalatic reaction. The induction period of this reaction with its autocatalytic cycle may well be completed within the first few seconds before it can be registered experimentally in a manometer.

Nevertheless, the study of azide-catalase strongly supports the view that the activity of free catalase involves changes in the valency of its haematin iron and that the ferrous catalase is probably reoxidized by molecular oxygen. So far azide-catalase has provided us with the best, if not the only, available line of approach to the experimental study of the mechanism of the catalase reaction.

If further evidence is called for it should be based upon the results of experiments with the enzyme rather than upon purely theoretical discussion of plausible reactions derived from the study of the activity of inorganic catalysts showing only superficial resemblance to catalase.

\section{- SUMMARY}

1. Catalase combines reversibly with azide. As in the case of free catalase, the haematin iron of azide-catalase is trivalent.

2. The formation of this compound requires one molecule of azide per iron atom of catalase haematin.

3. Azide-catalase resembles free catalase in colour, absorption spectrum, magnetic susceptibility and resistance to reducing agents such as $\mathrm{Na}_{2} \mathrm{~S}_{2} \mathrm{O}_{4}$.

4. On addition of $\mathrm{H}_{2} \mathrm{O}_{2}$ to azide-catalase, the colour of the compound turns from greenish brown to red and its absorption band in the red is replaced by two bands at 587 and $559 \mathrm{~m} \mu$.

5. That the compound thus obtained contains iron in the divalent state is supported by the following evidence:

(a) The compound is stable only in absence of $\mathrm{O}_{2}$; in its presence it rapidly reoxidizes to the original azide-catalase.

(b) Like other ferrous haematin derivatives it reacts with $\mathrm{CO}$, forming a well-defined compound which is more stable in air.

(c) The decomposition of $\mathrm{H}_{2} \mathrm{O}_{2}$ by azide-catalase is inhibited by $\mathrm{CO}$ and this inhibition is abolished by light.

(d) Cyanide has a much greater affinity for catalase than has azide and can therefore displace it from ferric azide-catalase. After treatment of azidecatalase with $\mathrm{H}_{2} \mathrm{O}_{2}$, however, cyanide produces no such effect.

(e) Contrary to the view expressed by Theorell \& Agner (1942), the absorption spectrum of reduced azide-catalase is quite different from that of ferric cyan-catalase. 
(f) Measurements of the magnetic susceptibility of the compound in $\mathrm{N}_{2}$ and in $\mathrm{CO}$ carried out by Theorell \& Agner do not in any way contradict the view that the iron of this compound is in the ferrous state.
6. The close relationship between the properties of azide-catalase and the free enzyme suggests that the catalytic decomposition of $\mathrm{H}_{2} \mathrm{O}_{2}$ by catalase involves a cyclical reduction and oxidation of its iron, as has been established in the case of azide-catalase.

\title{
REFERENCES
}

Agner, K. (1938). Biochem. J. 32, 1702.

Agner, K. (1941). Acta physiol. Scand. 2, Suppl. vir. Agner, K. (1942). Ark. Kemi Min. Geol. 16 A, no. 6. Coryell, C. D. (1939). J. phys. Chem. 43, 841.

Dounce, A. L. \& Frampton, O. D. (1939). Science, 89, 300. Dounce, A. L. \& Howland, J. W. (1943). Science, 97, 21.

Euler, H. v. (1934). Chemie der Enzyme. München: Bergmann.

Euler, H. v. \& Josephson, K. (1927). Liebigs Ann. 452, 158.

Haber, F. \& Willstätter, R. (1931). Ber. dtsch. chem. Ges. 64, 2844.

Keilin, D. (1930). Proc. roy. Soc. B, 106, 418.

Keilin, D. (1936). Proc. roy. Soc. B, 121, 165.

Keilin, D. \& Hartree, E. F. (1935). Proc. roy. Soc. B, 117, 1.

Keilin, D. \& Hartree, E. F. (1936). Proc. roy. Soc. B, $121,173$.

Keilin, D. \& Hartree, E. F. (1938). Proc. roy. Soc. B, $124,397$.

Keilin, D. \& Hartree, E. F. (1939). Proc. roy. Soc. B, $127,167$.

Keilin, D. \& Hartree, E. F. (1943). Nature, Lond., $152,626$.

Kuhn, R. \& Wassermann, A: (1933). Liebigs Ann. 503, 203.
Lemberg, R. \& Legge, J. W. (1943). Biochem. J. 37, 117.

Lemberg, R., Legge, J. W. \& Lockwbod, W. H. (1941). Biochem. J. 35, 339.

Lemberg, R., Norrie, M. \& Legge, J. W. (1939). Nature, Lond., 144, 551.

Pauling, L. (1942). The Nature of the Chemical Bond. New York: Cornell University Press.

Pauling, L. \& Coryell, C. D. (1936a). Proc. nat. Acad. Sci., Wash., 22, 159.

Pauling, L. \& Coryell, C. D. (1936b). Proc. nat. Acad. Sci., Wash., 22, 210.

Sumner, J. B. (1941). Advances in Enzymology, 1, 163.

Sumner, J. B. \& Dounce, A. L. (1937). J. biol. Chem. $121,417$.

Sumner, J. B., Dounce, A. L. \& Frampton, O. D. (1940). J. biol. Chem. 136, 343.

Theorell, H. \& Agner, K. (1942). Ark. Kemi Min. Geol. $16 \mathrm{~A}$, no. 7.

Weiss, J. (1937). J. phys. Chem. 41, 1107.

Zeile, K., Fawaz, G. \& Ellis, V. (1940). Hoppe-Seyl. Z. 263, 181.

Zeile, K. \& Hellström, H. (1930). Hoppe-Seyl. Z. 192, 171.

\section{The Chemical Conversion of Di-iodotyrosine into Thyroxine}

\author{
BY C. R. HARINGTON AND ROSALIND V. PITT RIVERS, National Institute for Medical Research, \\ Hampstead, N.W. 3
}

(Received 3 F'ebruary 1945)

The fact observed by Ludwig \& von Mutzenbecher (1939), that iodination of certain proteins under controlled conditions gave rise to products from which thyroxine could be isolated, could be explained in one of two ways: either the proteins in question contained thyronine as a hitherto unrecognized constituent which was directly converted by iodination into thyroxine, or the tyrosine of the protein was iodinated to 3:5-di-iodotyrosine, part of which subsequently formed thyroxine. The latter mode of formation of thyroxine had indeed been suggested by one of us many years ago (Harington \& Barger, 1927) and evidence, both chemical and biological, which had accumulated over a number of years (cf. Harington, 1944) favoured the supposition; its likelihood was further increased by the later observation of von Mutzenbecher (1939) that di-iodotyrosine on incubation in alkaline solution spontaneously gave rise to traces of thyroxine.
The over-all reaction representing the conversion of di-iodotyrosine into thyroxine can be crudely formulated as involving the loss, between two molecules of di-iodotyrosine, of one molecule of alanine; in such a formulation no oxidative process need necessarily be assumed. In actual fact, however, it is scarcely possible to conceive such an intermolecular dissociation, and it seems almost certain that the first stage of the reaction must be an oxidative process whereby the molecule of di-iodotyrosine is converted into one or more less stable and more reactive forms.

The supposition that oxidation must play a part is strengthened by a further consideration. By altering the conditions of iodination of a protein two entirely different results can be obtained. If the experiment is conducted as rapidly as possible in cold concentrated solution in presence of excess of ammonia the predominant and sometimes the 